\title{
Psychometric properties of SDHQ-53, the Persian version of social development and health questionnaire within Iranian samples
}

\author{
Ali Ismaeli ${ }^{1}$, Abdolrahim Asadollahi 2,3,* \\ 1University of Applied Science and Technology, Tehran, Iran \\ ${ }^{2}$ Australian Centre for Quality of Life, Deakin University, Melbourne, Australia \\ 3Inst. of SDHP, Shiraz University of Medical Sciences, Shiraz, Iran
}

\section{ARTICLE INFO}

\section{Article history:}

Received 15 June 2016

Received in revised form

15 October 2016

Accepted 17 October 2016

Keywords:

Validity and reliability

SDHQ-53

Health and social development Iran

\begin{abstract}
A B S T R A C T
The modernity and social development is an important issue within developing societies like the Middle Eastern countries. The SDHQ-53 is selfconstructed scale measuring tendency to health and social development upon Iranian-based society. Psychometric properties of SDHQ-53 across urban dwellers in the northwest Iran and discuss its role in the detection of quality of development. About 876 respondents (Mean= 36.3 \pm 3.71 ) were sampled from the eight municipal zones in Tabriz city and replied to SDHQ53. External and criterion validity was calculated by correlation to the four questionnaires. The SDHQ-53 includes 11 subscales: life satisfaction and health, fatalism, socio-cultural alienation, need for achievement, using media, innovation and creative personality, limited good, individualism, socioeconomic participation, dependency, particularism. There was significant difference within sample groups regarding main variables $(\rho<.05)$. The coefficients of Cronbach's alpha $(\alpha=.89)$, convergent validity (.81), divergent validity $(-.21)$, external validity with overall score of five external scales (Mean=.87), and criterion validity (.78) were estimated, which were significant at $\rho<.01$. The exploratory factor analysis demonstrated that the SDHQ-53 is organized into 11 factors, which clarifies 92 per cent of the scale's variance. Second-order confirmatory factor analysis pointed out that the factor is well matched up onto a principal factor. Consequently, the 11factors model was well appropriate for the data by the fit index techniques (AGFI $=.88, \mathrm{GFI}=.95$, RMSEA $=.002$, IFI $=.93, \mathrm{NFI}=.96, \mathrm{CFI}=.96)$. The results pointed to the well-adjusted reliability and psychometric properties of the SDHQ-53 and its usefulness for the relevant studies as well.
\end{abstract}

(C) 2016 The Authors. Published by IASE. This is an open access article under the CC BY-NC-ND license (http://creativecommons.org/licenses/by-nc-nd/4.0/).

\section{Introduction}

"Tradition" and "modernity" are widely used as polar opposites in a linear theory of social change. It is incorrect to view traditional societies as static, normatively consist, or structurally homogeneous. The relations between the traditional and the modern do not necessarily involve displacement, conflict, or exclusiveness. Modernity does not necessarily weaken tradition. Both tradition and modernity form the bases of ideologies and movements in which the polar opposites are converted into aspirations, but traditional forms may

\footnotetext{
* Corresponding Author.

Email Address: a.asadollahi@hotmail.co.uk (A. Asadollahi)

https://doi.org/10.21833/ijaas.2016.10.010

2313-626X/C 2016 The Authors. Published by IASE.

This is an open access article under the CC BY-NC-ND license

(http://creativecommons.org/licenses/by-nc-nd/4.0/)
}

supply support for, as well as against, change (Marston, 2000).

The social and cultural aspects of development are a striking degree, the same syndrome of attitudes, values, and ways of acting-such as openness to new experience, independence from parental authority, and taking an active part in civic affairs-defines the modern man in each of the communities and in all the occupational groups of cultivator, craftsman, and industrial worker. Education is the most powerful factor in making men modern, but occupational experience in large-scale organizations, and especially in factory work, makes a significant contribution in "schooling" men in modern attitudes and in teaching them to act like modern men (Asadollahi et al., 2011). Modern men in developing countries not only have modern attitudes, but they can be shown to behave differently. Despite popular impressions to the contrary, exposure to the influence of migration and 
modern institutions does not lead to psychic distress (Lobao and Hooks, 2015).

Sociologists have long studied subnational development across the globe focusing on community and modern human that contribute to spatial inequality and uneven development. Subnational research is central to development sociology's concern with the present neoliberal stage of capitalism and to numerous theoretical, substantive, cultural and social development, and policy issues that revolve around poverty and prosperity within the nation (Lobao and Hooks, 2015). Yet the body of work faces a number of challenges. Research is fragmented and its potential for building development of an instrument has overlooking on social and cultural progress. It provides a critical and statistical analysis of this modern and tradition focusing on its theoretical development on modernity and identifying a wave of shifts in social and cultural structure. Over the recent years, scholars in development studies have been paying increasing theoretical and empirical attention to understanding the ways in which the developing scale in measurement the human modernity and life (Asadollahi et al., 2016; Armer and Schnaiberg, 1972). Overwhelmingly, this work reflects on operational approach. In this article we develop and emphasis on the necessity of scale construction and argue for enlarging our scope for understanding scale to include the complex processes of social and cultural development. The study was investigated to the standards of social development and health inventory in the human life, the adequate version (SDHQ-53) (2015) within young and adults to introduce a relevant criterion. The measurement of external validity had contained correlating relation of the five scales with SDHQ-53 Inventory, to check the properties of the development specific dimensions.

\section{Materials and methods}

About 472 men and 404 women with age range of 15 to 67 and with the mean age of $36.3 \pm 3.71$ were sampled with the cluster-ratio sampling method from the eight municipal zones of Tabriz city, provincial capital of the Eastern Azerbaijan in the northwest Iran. The samples replied to the 53 items of SDHQ-53. The SDHQ-53 questionnaire mainly consists of a 53-item scale regarding cultural and social development that was investigated by authors and literature reviews $[2,4,7,12-13,20,22,24,27$, 29) It was developed in one version. The 53 items is most common used version of SDHQ-53. Each item in the scale has several responses i.e. five response option from 1 = strongly agree to $5=$ strongly disagree. If the 53 items are completed, a scale score ranging from 53 (having the most agreement to the modernity and social development in society) to 265 (having the most traditional opinions), can be calculated. The SDHQ-53 contains 53 items on the following domains: LSH: Life Satisfaction and Health, F: Fatalism, SCA: Socio-Cultural Alienation, N4A:
Need for Achievement, UM: Using Media, IandC: Innovation and Creative Personality, LG: Limited Good, Individualism and SCP: Socio-Economic Participation, D: Dependency, P: Particularism.

External and Criterion Validity: It was estimated by the correlations of overall scores of SDHQ-53 and its domains to the 5 similar instruments like PSE-Q inventory (Schultheiss et al., 2009), Need to Belong Scale (Leary et al., 2013), Motive Profile for the Zurich Model (MPZM) (Schönbrodt et al., 2009), GOALS inventory (Pöhlmann and Brunstein, 1997), Big Five Inventory (BFI-10) (Rammstedt, 2007). The Pearson's correlation coefficients were used to measure the relationship between scales of SDHQ-53 and the five external scales. Strong correlations were expected between domains and scales with the same content.

a) PSE-Q inventory (Schultheiss et al., 2009). This newly developed questionnaire with its subscales for power, achievement, and affiliation combines the motive stimulating pictures of a classic PSE task with fixed questions that address the participant's reactions to these pictures (e.g., "I would try to influence or persuade the other person(s)" for the power motive). Participants answer with a binary choice (yes/no). The PSE-Q was developed to provide a measure of explicit motives that is structurally as close as possible to the measurement of developing motives using the Picture Story Exercise (PSE) (Winter, 1991).

b) Need to Belong Scale (Leary et al., 2013). The need to belong (NTB) is a prominent construct in social psychology (Baumeister and Leary, 1995). Its definition closely resembles typical definitions of the affiliation and intimacy motives: "a pervasive drives to form and maintain at least a minimum quantity of lasting, positive, and significant interpersonal relationships" (Baumeister and Leary, 1995). This strand of theorizing usually focuses on the general tendency and the fundamentality of the need to belong for any person. Interindividual differences, specifically the dissociation of the fundamental motivational tendencies of approach and avoidance, have rarely been taken into consideration (Gere and MacDonald, 2010; Gable, 2006; Barber et al., 2012). Some researchers, however, have used a questionnaire to measure interindividual differences in the need to belong scale (NTBS) (Leary et al., 2013; Renner, 2006). This scale assesses the NTB on 10 items such as "My feelings are easily hurt when I feel that others do not accept me."

c) GOALS inventory (Pöhlmann and Brunstein, 1997). In addition to the scales already employed in the study, the additional scales were included: enterprise and altruism.

d) Motive Profile for the Zurich Model (MPZM) Schönbrodt et al., 2009). This inventory provides five motive scales based on the Zurich model of social development (Gubler and Bischof, 1991): dependency, enterprise, power, prestige, and achievement. Each scale consists of six items. 
e) Big Five Inventory (BFI-10) (Rammstedt, 2007). Finally, a short measure with two items for each dimension of the Big Five personality factors was included.

Procedures: The printed version of the SDHQ-53 was mailed to the samples as part of an assessment battery with a postage-paid business-reply envelope. The samples whose ethnicity was classified as Azeri at society received both an Azeri and a Persian version of the SDHQ-53 in their mailing. It may help them to simply recognise and understand the scientific words, as a research has acclaimed it is necessity while research in minority groups with bilingual language (Asadollahi et al., 2013). The respondents were paid $\$ 10$ for completing the assessment packet. The filled questionnaires were gathered during 5 months from December 2015 to May 2016.
Setting and Participants: From the eight municipal zones of Tabriz city, provincial capital of the Eastern Azerbaijan in the northwest Iran, about 880 women and men responded to the SDHQ-53. Of the 880 responders, 876 had responded to all of the 53 items used in the inventory and included in the analysis. The mean age of the samples was $36.3 \pm 3.71$ (range 15-671) years of age.

\section{Results}

About 876 urban dwellers were the samples of the study, 472 men (55.88\%) and 404 women $(46.02 \%)$ with a mean age of 36.3 years of old $(S D=3.71)$. All of patients were replied to the 6 inventories of study, SDHQ-53 PSE-Q, need to belong scale, motive profile for the Zurich model, goals inventory, and big five inventory. The demographic characteristics are shown in Table 1.

Table 1: Frequency distribution and comparison of samples' demographic and background profiles by gender $(\mathrm{N}=876, \rho \leq$

0.05.)

\begin{tabular}{|c|c|c|c|c|c|c|}
\hline Categories & Sub Items & $\mathrm{N}$ & $\%$ & Male & Female & $\chi^{2 / \rho}$ \\
\hline \multirow{2}{*}{ Gender } & Male & 472 & 53.88 & - & - & \multirow{2}{*}{$1.205 / .000$} \\
\hline & Female & 404 & 46.02 & - & - & \\
\hline \multirow{3}{*}{ Age $($ Mean $=36.3, \mathrm{SD}=3.71)$} & 15-30 (Youths) & 299 & 49.32 & 20 & 16 & \multirow{3}{*}{$2.105 / .000$} \\
\hline & 31-50 (Middle-aged) & 361 & 28.77 & 13 & 8 & \\
\hline & $\geq 51$ (Older adults) & 216 & 21.92 & 8 & 8 & \\
\hline \multirow{3}{*}{ Ethnicity } & Persian & 285 & 41.10 & 15 & 15 & \multirow{3}{*}{$3.112 / .000$} \\
\hline & Azeri & 554 & 30.14 & 18 & 4 & \\
\hline & Others & 37 & 28.77 & 16 & 5 & \\
\hline \multirow{6}{*}{ Educational status } & No formal school & 34 & 3.8 & 12 & 22 & \multirow{6}{*}{$17.5 / .001$} \\
\hline & Only reading & 78 & 8.9 & 40 & 38 & \\
\hline & Primary & 138 & 15.75 & 111 & 27 & \\
\hline & Middle school & 136 & 15.75 & 78 & 58 & \\
\hline & High school & 379 & 43.26 & 210 & 169 & \\
\hline & Graduated & 111 & 12.67 & 71 & 40 & \\
\hline \multirow{6}{*}{ Marital status } & Divorced & 56 & 7.31 & 26 & 30 & \multirow{6}{*}{$38.4 / .002$} \\
\hline & Widowed & 39 & 3.72 & 9 & 30 & \\
\hline & Separated & 12 & 1.02 & 2 & 10 & \\
\hline & Married & 685 & 78.19 & 248 & 437 & \\
\hline & Never married & 8 & .81 & 8 & 0 & \\
\hline & Living with other & 76 & 8.9 & 16 & 60 & \\
\hline \multirow{2}{*}{ Family members $($ Mean $=5.7, \mathrm{SD}=1.34)$} & $\leq 5$ persons & 635 & 71.58 & 956 & 279 & \multirow{2}{*}{$23.8 / .005$} \\
\hline & $\geq 6$ persons & 241 & 28.42 & 132 & 109 & \\
\hline \multirow{3}{*}{ Economic support and pensioning } & Nothing & 52 & 7.31 & 10 & 42 & \multirow{3}{*}{$31.3 / .000$} \\
\hline & Public & 685 & 78.19 & 421 & 264 & \\
\hline & Private & 139 & 15.75 & 89 & 50 & \\
\hline \multirow{5}{*}{$\begin{array}{l}\text { Range of Financial Support upon Urban Poverty } \\
\text { Ratio a }(\text { Mean }=936439.79, S D=1.48)\end{array}$} & Nothing & 52 & 7.31 & 10 & 42 & \multirow{5}{*}{$25.5 / .000$} \\
\hline & $\leq 990,000$ & 238 & 28.30 & 112 & 126 & \\
\hline & $1000000-4500000$ & 328 & 28.04 & 204 & 124 & \\
\hline & $4510000-7990000$ & 157 & 16.56 & 107 & 50 & \\
\hline & $\geq 8000000$ & 101 & 12.31 & 90 & 11 & \\
\hline \multirow{8}{*}{ Municipal Zones b } & 1= Middle Class & 120 & 12.67 & 65 & 55 & \multirow{8}{*}{$41.01 / .009$} \\
\hline & 2= Developed & 129 & 15.20 & 100 & 29 & \\
\hline & 3= Developed & 109 & 12.22 & 90 & 19 & \\
\hline & 4= Undeveloped & 112 & 12.29 & 80 & 32 & \\
\hline & 5= Undeveloped & 104 & 12.18 & 70 & 34 & \\
\hline & $6=$ Middle Class & 101 & 12.01 & 81 & 20 & \\
\hline & $7=$ Middle Class & 103 & 12.01 & 73 & 30 & \\
\hline & 8= Undeveloped & 98 & 9.02 & 62 & 36 & \\
\hline
\end{tabular}

a. Based on Iranian Rials currency and 1 US $\$=32060$ IR Rials in 2016. b. They are economically divided into three parts i.e. poor and undeveloped $=29.6 \%$ (zone 4,5 , and 8), middle class $=48.6 \%$ (zone 1, 6, and 7), wealthy and developed $=21.8 \%$ (zone 2 and 3 ) regarding income of citizens and urban facilities based on Provincial Report of AzSCC (2011)

The comparing SDHQ-53 overall score made between males and females regarding their attitude on modernity, intimacy, social and cultural development in the community within samples. 
Internal Consistency: The coefficients of Cronbach's alpha $(\alpha=.89)$, convergent validity (.81), divergent validity $(-.21)$, and criterion validity $(.78)$ were estimated, which were significant at $\rho<.01$. The discriminative power in the SDHQ-53 of sub-scales with overall score using Kolmogorov-Smirnov and
Shapiro-Wilk tests of normality demonstrated an almost normal distribution (Table 2). Mean overall score was $112.5(\mathrm{CI}=67-201)$, Median $=118$, and SD $=9.42$. Discriminative power testing showed that domains have had an almost normal distribution (Table 2).

Table 2: Descriptive statistics and discriminative power in the SDHQ-53 of sub-scales with overall score

\begin{tabular}{|c|c|c|c|c|c|c|c|c|c|}
\hline Domains (Item Number) & $\begin{array}{l}\text { No. of } \\
\text { items }\end{array}$ & Mean $(95 \% \mathrm{CI})^{\mathrm{a}}$ & Median & SD & Cronbach's $\alpha$ & $\mathrm{KS}^{\mathrm{b}}$ & SVc & df & $\rho$ \\
\hline $\begin{array}{c}\text { Life } \\
\text { Satisfaction and Health }\end{array}$ & 4 & $14.5(28-81)$ & 13 & 6.04 & .83 & .094 & .089 & 841 & .0001 \\
\hline Fatalism & 7 & $23.2(21-72)$ & 24 & 8.01 & .85 & .074 & .087 & 842 & .0001 \\
\hline $\begin{array}{l}\text { Socio-Cultural } \\
\text { Alienation }\end{array}$ & 4 & $18.7(39.2-87.2)$ & 17 & 1.01 & .79 & .149 & .122 & 842 & .0001 \\
\hline $\begin{array}{c}\text { Need for } \\
\text { Achievement }\end{array}$ & 3 & $10(11.25-28.75)$ & 11 & 9.21 & .73 & .092 & .071 & 841 & .0001 \\
\hline Using Media & 4 & $12.7(32.8-68.6)$ & 12 & 3.30 & .81 & .073 & .088 & 842 & .0002 \\
\hline $\begin{array}{c}\text { Innovation and } \\
\text { Creative Personality }\end{array}$ & 4 & $12.28(14.86-74.7)$ & 13 & 2.82 & .87 & .147 & .133 & 841 & .0001 \\
\hline Limited Good & 3 & $9.84(37.42-82.26)$ & 9 & 5.33 & .88 & .148 & .145 & 841 & .0002 \\
\hline Individualism & 4 & $12.32(13.83-70.7)$ & 12 & 4.67 & .88 & .149 & .152 & 841 & .0001 \\
\hline $\begin{array}{l}\text { Socio-Economic } \\
\text { Participation } \\
\end{array}$ & 6 & 33.18 (13.32-73.2) & 32 & 3.87 & .89 & .083 & .038 & 841 & .0002 \\
\hline Dependency & 6 & 32.28 (13.76-71.7) & 32 & 5.23 & .89 & .149 & .132 & 842 & .0002 \\
\hline Particularism & 8 & $42.28(13.86-70.7)$ & 43 & 8.18 & .90 & .073 & .088 & 841 & .0002 \\
\hline Total Score & 53 & $112.5(67-201)$ & 118 & 9.42 & .89 & .083 & .091 & 842 & .0001 \\
\hline
\end{tabular}

a. The score range $=53-265 . \mathrm{N}=876$. b. Kolmogorov-Smirnov test of normality. c. Shapiro-Wilk test of normality

Regarding criterion validity, Pearson's correlation coefficients were significant and appropriate for all sub-domains of SDHQ-53 and other five external scales. This finding could suggest some specificity of these domains. Table 3 summarizes the appropriate correlation of the six questionnaires' subscales.

Table 3: Pearson correlations between SDHQ-53 and total scores of criterion-related scales $(\rho<.05$.

\begin{tabular}{|c|c|c|c|c|c|}
\hline Domains & TB5I & TMPZM & TGI & .501 & .506 \\
\hline LSH & .561 & .474 & .572 & .469 & .436 \\
\hline F & .479 & .438 & .571 & .349 & .514 \\
\hline SCA & .498 & .585 & .371 & .435 & .446 \\
\hline N4A & .478 & .458 & .266 & .441 & .438 \\
\hline UM & .548 & .324 & .371 & .435 & .446 \\
\hline LG & .578 & .458 & .577 & .601 & .306 \\
\hline SCP & .501 & .474 & .471 & .569 & .486 \\
\hline D & .479 & .438 & .371 & .435 & .446 \\
\hline P & .578 & .458 & .338 & .338 & .428 \\
\hline TSDHQ-53 & .549 & .431 & .571 & .535 & .416 \\
\hline
\end{tabular}

LSH: Life Satisfaction and Health, F: Fatalism, SCA: Socio-Cultural Alienation, N4A: Need for Achievement, UM: Using Media, IandC: Innovation and Creative Personality, LG: Limited Good, Individualism, SCP: Socio-Economic Participation, D: Dependency, P: Particularism, TSDHQ-53: Total scores of overall SDHQ-53, TB5I: Total scores of overall Big Five Inventory (BFI-10) (Rammstedt, 2007), TMPZM: Total scores of overall Motive Profile for the Zurich Model (Schönbrodt et al., 2009), TGI: Total scores of overall GOALS Inventory (Pöhlmann and Brunstein, 1997), TNBS: Total scores of overall Need to Belong Scale (Leary et al., 2006), TPSE-QI: Total scores of overall PSE-Q Inventory (Schultheiss et al, 2009)

Kaiser-Meyer-Olkin Criterion and Bartlett's Test of Sphericity: The Kaiser-Meyer-Olkin Measure of Sampling Adequacy (KMO) statistic is the most common test used to determine whether the scale under investigation can be factored (Osborne and Costello, 2005). This test evaluates whether the correlations are chance correlations or are significant enough to be factored (Worthington and Whittaker, 2006). The Kaiser-Meyer-Olkin Measure (KMO) for the data was determined to be .902 . Values of .60 and above are required for an appropriate factor analysis, with values closer to 1.0 as better (Worthington and Whittaker, 2006).
Therefore according to the KMO criteria, the SDHQ53 is able to undergo a factor analysis (Table 4). Another test that can be used to determine the factorability of the scale under investigation is Barlett's test of Sphericity, which determines whether or not variables are, uncorrelated (Kraha et al., 2012).

Table 4: Bartlett's test of Sphericity

\begin{tabular}{|c|c|}
\hline Approx. Chi-Square & 4500.249 \\
\hline $\mathrm{df}$ & 865 \\
\hline Sig. & .000 \\
\hline KMO test & .902 \\
\hline
\end{tabular}


Contrast Validity: The exploratory factor analysis demonstrated that the 53-items of SDHQ-53 for the samples are organized into 11 factors (LSH: Life Satisfaction and Health, F: Fatalism, SCA: SocioCultural Alienation, N4A: Need for Achievement, UM: Using Media, IandC: Innovation and Creative Personality, LG: Limited Good, Individualism, SCP: Socio-Economic Participation, D: Dependency, P:
Particularism) which clarify 94 per cent of the scale's variance. Second-order confirmatory factor analysis pointed out that the factors were well matched up onto a principal factor. According to the Table 5, the rotated factor matrix pattern of Varimax for the SDHQ-53's subscale questions was considered. Those questions with factor loadings above .85 were selected.

Table 5: Varimax rotated factors matrix of the SDHQ-53 ( $n=876$, only factor loadings $\geq .05)$

\begin{tabular}{|c|c|c|c|c|c|c|c|c|c|c|c|}
\hline \multirow{2}{*}{$\begin{array}{l}\text { No. of } \\
\text { Item }\end{array}$} & \multirow[b]{2}{*}{ Domains } & \multirow[b]{2}{*}{ Mean } & \multirow[b]{2}{*}{ SD } & \multicolumn{8}{|c|}{ Components } \\
\hline & & & & $\begin{array}{c}\text { Factor } \\
1\end{array}$ & $\begin{array}{c}\text { Factor } \\
2\end{array}$ & $\begin{array}{c}\text { Factor } \\
3\end{array}$ & $\begin{array}{c}\text { Factor } \\
4\end{array}$ & $\begin{array}{c}\text { Factor } \\
5\end{array}$ & $\begin{array}{c}\text { Factor } \\
6\end{array}$ & $\begin{array}{c}\text { Factor } \\
7\end{array}$ & $\begin{array}{c}\text { Factor } \\
8\end{array}$ \\
\hline \multirow{4}{*}{$\begin{array}{c}9 \\
10 \\
11 \\
12\end{array}$} & \multirow{4}{*}{$\begin{array}{c}\text { Life } \\
\text { Satisfaction and } \\
\text { Health }\end{array}$} & .34 & & .89 & & & & & & & \\
\hline & & .29 & .46 & .84 & & & & & & & \\
\hline & & .31 & .47 & .85 & & & & & & & \\
\hline & & .31 & .47 & .88 & .87 & & & & & & \\
\hline \multirow{4}{*}{$\begin{array}{l}39 \\
40 \\
41 \\
42\end{array}$} & \multirow{7}{*}{ Fatalism } & .29 & .37 & & .88 & & & & & & \\
\hline & & .40 & .46 & & .79 & & & & & & \\
\hline & & .24 & .40 & & .78 & & & & & & \\
\hline & & .33 & .49 & & .92 & & & & & & \\
\hline 43 & & .36 & .43 & & .92 & & & & & & \\
\hline 44 & & .09 & .47 & & .89 & & & & & & \\
\hline 45 & & .24 & .24 & & .90 & & & & & & \\
\hline 5 & \multirow{4}{*}{$\begin{array}{l}\text { Socio-Cultural } \\
\text { Alienation }\end{array}$} & .28 & .47 & & & .87 & & & & & \\
\hline 6 & & .17 & .43 & & & .87 & & & & & \\
\hline 7 & & .09 & .38 & & & .88 & & & & & \\
\hline 8 & & .09 & .28 & & & .89 & & & & & \\
\hline 17 & \multirow{3}{*}{$\begin{array}{c}\text { Need for } \\
\text { Achievement }\end{array}$} & .24 & .28 & & & & .87 & & & & \\
\hline 18 & & .26 & .43 & & & & .88 & & & & \\
\hline 19 & & .05 & .38 & & & & .89 & .85 & & & \\
\hline 1 & \multirow{4}{*}{ Using Media } & .24 & .44 & & & & & .87 & & & \\
\hline 2 & & .27 & .38 & & & & & .88 & & & \\
\hline 3 & & .31 & .46 & & & & & .90 & .77 & & \\
\hline 4 & & .33 & .31 & & & & & .89 & & & \\
\hline 13 & \multirow{4}{*}{$\begin{array}{l}\text { Innovation and } \\
\text { Creative } \\
\text { Personality }\end{array}$} & .24 & .28 & & & & & & .87 & & \\
\hline 14 & & .26 & .43 & & & & & & .87 & & \\
\hline 15 & & .05 & .38 & & & & & & .88 & & \\
\hline 16 & & .24 & .28 & & & & & & .91 & & \\
\hline 20 & \multirow{3}{*}{ Limited Good } & .26 & .43 & & & & & & & .81 & .74 \\
\hline 21 & & .05 & .38 & & & & & & & .87 & \\
\hline 22 & & .24 & .24 & & & & & & & .79 & .80 \\
\hline 23 & \multirow{4}{*}{ Individualism } & .28 & .47 & & & & & & & & .91 \\
\hline 24 & & .17 & .43 & & & & & & & & .92 \\
\hline 25 & & .09 & .38 & & & & & & & & .89 \\
\hline 26 & & .27 & .38 & & & & & & & & .89 \\
\hline
\end{tabular}

There are covariate between some items i.e. item No. 21 between factors No. 6 and 8, item No. 3 between factors No. 6 and 5, item No. 27 between factors No. 10 and 11 in the recent version of SDHQ53. It may acclaim that covariate item of the factors could be reconstructed as well (Thissen, 2000).

Eigenvalue Rule: Additionally, one of the other main criteria to determine how many factors have been extracted is the eigenvalue rule (DeVellis, 2016). This rule postulates that any factor with an eigenvalues less than 1.0 should not be retained (Wirth and Edwards, 2007). Table 6 depicts the eigenvalues after extraction and according to the eigenvalues, the researcher decided to retain 11 factors.

Consequently, the 11-factor model was appropriate for the data and the fit index techniques for adjusting the scale. The indexes of the model's goodness of fit refer to the integrity of the 11-factor model with data. The $\chi^{2}$ to degrees of freedom is less than 2 in efficient models. It is closer to zero and will be closer. The root mean square error of approximation (RMSEA) and standardized root mean residual (SRMR) must be less than .05 that indicate to good models. According to the Table 7, the model pointed out the goodness of fit of the model in the study $\left(\chi^{2} / \mathrm{df}=1.055, \mathrm{AGFI}=.88, \mathrm{GFI}=.95\right.$, RMSEA=.002, $\mathrm{IFI}=.93$, NFI= .96, CFI=.96).

As closer measure to 1 in the normed fit index (NFI), the comparative fit index (CFI), goodness-of-fit statistic (GFI), the incremental fit index (IFI), and the adjusted goodness of fit index (AGFI), they refer to the goodness and fit of model. They were more than .90 (Table 7).

\section{Discussion and conclusion}


The aim of the study is to look for the relevant instrument regarding common achievement to the modernity, social and cultural development within young and adults in the Iranian social context, even the issue still is challengeable. So, the social development and health questionnaire (SDHQ-53, 2016) was used and evaluated. The results stated to the well-adjusted psychometric properties, discriminative statistic, reliability, and validity of SDHQ-53 and usefulness of it in the relevant studies too. Regarding the external validity, correlation coefficients were significant and appropriate all subdomains of SDHQ-53 with the 5 external scales as well. Therefore, future researchers should not limit themselves to the western scales, but should also consider specific cultural factors (Hofer et al., 2010).
Table 6: the Eigenvalues after extraction, $n=876$

\begin{tabular}{|c|c|c|c|}
\hline Factors & \multicolumn{1}{c}{ Total Variance } & \multicolumn{1}{c|}{ Sig. } \\
\hline 1 & 8.89 & 28.83 & .000 \\
\hline 2 & 8.83 & 19.83 & \\
\hline 3 & 8.80 & 17.34 & \\
\hline 4 & 8.79 & 12.54 & \\
\hline 5 & 8.65 & 11.35 & \\
\hline 6 & 7.90 & 10.96 & \\
\hline 7 & 7.45 & 10.45 & \\
\hline 8 & 7.21 & 9.25 & \\
\hline 9 & 6.34 & 8.34 & \\
\hline 10 & 3.54 & 8.14 & \\
\hline 11 & 1.95 & 7.95 & \\
\hline 12 & .904 & 2.674 & \\
\hline 13 & .832 & 2.262 & \\
\hline 14 & .609 & 1.629 & \\
\hline 15 & .601 & 1.171 & \\
\hline 16 & .512 & .822 & \\
\hline
\end{tabular}

Table 7: The Goodness of fit indexes model

\begin{tabular}{|c|c|c|c|c|c|c|c|c|c|}
\hline Indexes & $\chi^{2}$ & df & $\chi^{2} / \mathrm{df}$ & AGFI & GFI & RMSEA & IFI & NFI & CFI \\
\hline Value & 142.35 & 86 & 1.055 & .88 & .95 & .002 & .93 & .96 & .96 \\
\hline
\end{tabular}

The version of SDHQ-53 illustrated appropriate satisfactory psychometric statistics, good reliability, high internal consistency, valuable discriminative characteristics. It has applicable level in the conceptual similarity to the same countries like Tajikistan, Azerbaijan, and Afghanistan. Regarding the findings of the study, the SDHQ-53 is appropriate for validity and reliability in the community of the Iranian society and it can be employed to measure need to achievement and modernity, social and cultural development. Additionally, it is applicable by sociologists, the experts in cultural and developing studies. Regarding the divergent background, it is first time suggested that in the future studies, the gender-related symptoms of modernity and development within minorities groups like Azeri people of Iran, which are compatible with communities like Iran's minority groups and other divergent communities in the Middle East and North Africa, be conducted and evaluated as well.

\section{Acknowledgements}

We wish to thank colleagues and the anonymous referees for their valuable comments.

\section{Authors' contributions}

AI contributed to the design, performed the interviews, interpreted data from the interviews and also has contributed to the design, interpretation, and discussion. AA analysed the data, wrote the draft and has revised the content, scientific writing. Both authors have approved the final manuscript as well.

\section{Conflict of interests}

The authors declare that they have no competing interests.

\section{Ethical considerations}

Ethical matters, e.g. Plagiarism, uninformed consent, misconduct, data fabrication and/or falsification, double publication and/or submission, redundancy, etc., have been totally observed by the authors.

\section{Patient consent}

Written and verbal consent of the samples was obtained before participating the study.

\section{References}

Armer M and Schnaiberg A (1972). Measuring individual modernity: a near myth. American Sociological Review, 37(3): 301-316.

Asadollahi A, Ahmad N, Valizadeh S and Baratvand M (2011). Social quality for aged people in Iran: towards developing theoretical scale. Canadian Social Science, 7(6):162-176.

Asadollahi A, Saberi LF and Faraji N (2013). Validity and reliability of male andropause symptoms self-assessment questionnaire among elderly males in Khuzestan province of Iran. Journal of Mid-Life Health, 4(4), 233-237.

Asadollahi A, Saberi M, Entezari M, Hoseini Z, Hasani SA, Saberi LF and Ismaeli A (2016). Iranian version of 4AT, an instrument for rapid delirium screening for later life. International Journal of Advanced and Applied Sciences, 3(4): 33-38.

AzSCC (2011). Annual Population Report, provincial section. Eastern Azerbaijan Statistic \& Census Centre, Rep. No. AzSCC-43B2-2011. Tabriz, Iran.

Barber LK, Grawitch MJ and Munz DC (2012). Disengaging from a task - Lower self-control or 
adaptive self-regulation. Journal of Individual Differences, 33(2): 76-82.

Baumeister RF and Leary MR (1995). The need to belong: desire for interpersonal attachments as a fundamental human motivation. Psychological bulletin, 117(3):497-529.

DeVellis RF (2016). Scale development: Theory and applications. $4^{\text {th }}$ Edition, Sage Publications Inc., California, USA.

Gable SL (2006). Approach and avoidance social motives and goals. Journal of personality, 74(1): 175-222.

Gere J and MacDonald G (2010). An update of the empirical case for the need to belong. Journal of Individual Psychology, 66(1): 93-115.

Gubler MR and Bischof N (1991). A system perspective on infant developments. In Lamb ME and Keller $\mathrm{H}$ (Eds). Infant Developments: Perspectives from German-speaking countries: 35-66. Lawrence Erlbaum Associates, Hillsdale, USA.

Hofer J, Busch H, Bond MH, Li M and Law R (2010). Effects of motive-goal congruence on well-being in the power domain: Considering goals and values in a German and two Chinese samples. Journal of Research in Personality, 44(5): 610620.

Kraha A, Turner H, Nimon K, Zientek LR and Henson RK (2012). Tools to support interpreting multiple regression in the face of Multicollinearity. Frontiers in Psychology, 3: 23-31. https://doi.org/10.3389/fpsyg.2012.00044.

Leary MR, Kelly KM, Cottrell CA and Schreindorfer LS (2013). Individual differences in the need to belong: Mapping the Nomological network. Journal of Personality Assessment, 95(6):610-24.

Lobao L and Hooks G (2015). Development sociology at the subnational scale; open questions about state and market processes across the United States. Sociology of Development, 1(1):43-76.

Marston SA (2000). The social construction of scale. Progress in Human Geography, 24(2), 219-242.

Osborne JW and Costello AB (2009). Best practices in exploratory factor analysis: Four recommendations for getting the most from your analysis. Pan-Pacific Management Review, 12(2): 131-146.

Pöhlmann K and Brunstein JC (1997). Goals: Ein Fragebogen zur Erfassung von Lebenszielen. Diagnostica, 43: 63-79. [In German]

Rammstedt B (2007). The 10-Item big five inventory: Norm values and investigation of sociodemographic effects based on a German population representative sample. European Journal of Psychological Assessment, 23(3): 193201.

Renner B (2006). Curiosity about people: The development of a social curiosity measure in adults. Journal of Personality Assessment, 87(3): 305-316.

Schönbrodt FD, Unkelbach S and Spinath FM (2009). Broad motives in short scales: a questionnaire for the Zurich Model of social motivation. European Journal of Psychological Assessment, 25(3): 141149.

Schultheiss OC, Yankova D, Dirlikov B, and Schad DJ (2009). Are implicit and explicit motive measures statistically independent? A fair and balanced test using the Picture Story Exercise and a cue-and response-matched questionnaire measure. Journal of Personality Assessment, 91(1): 72-81.

Thissen D (2000). Reliability and measurement precision. In Wainer $\mathrm{H}$, Dorans $\mathrm{N}$, Eignor $\mathrm{D}$, Flaugher R, Green B, Mislevy R, Steinberg L and Thissen D (Eds.), Computerized adaptive testing: A primer: 159-184. 2nd Edition, Lawrence Erlbaum Associates Hillsdale, USA.

Winter DG (1993). Power, affiliation, and war: Three tests of a motivational model. Journal of Personality and Social Psychology, 65(3): 532545.

Wirth RJ and Edwards MC (2007). Item factor analysis: Current approaches and future directions. Psychological Methods, 12(1): 58-79.

Worthington RL and Whittaker TA (2006). Scale development research: A content analysis and recommendations for best practices. The Counselling Psychologist, 34(6): 806-838. 